\title{
Türkiye'nin Farklı İklim Koşullarında Isıl Konfor Sıcaklıklarına Bağlı Olarak Konutların Enerji Performanslarının Değerlendirilmesi
}

\author{
Ebru Hancioğlu Kuzgunkaya ${ }^{1}$, Nurdan Yildirim ${ }^{2 *}$, Gulden Gokçen Akkurt ${ }^{3}$
}

\section{ÖZ}

Isıl konfor, insanın yapısı, yaşı, cinsiyeti gibi kişisel parametrelerin yanı sıra çevresel parametrelere de bağlıdır. Isıtma, soğutma ve havalandırma sistemlerinin çalışma şekli ve dış hava sıcaklıkları ısıl konfor için önemli parametrelerdir. Fanger deneysel çalışmalar sonucu "tahmini ortalama oy (PMV)" olarak adlandırılan bir gösterge oluşturmuş ve PMV=0’1 konfor için en iyi değer olarak belirlemiştir. Bu çalışmada, farklı iklim bölgelerinden dört il seçilerek, her bir il için ısıl konfor sıcaklıkları belirlenmiş ve bu 1sıl konfor sıcaklıklarındaki enerji performansları değerlendirilmiştir. Isıtma ve soğutma sistemi için kişisel kontrole izin verilmeyen tam mekanik kontrollü sistem seçilmiş, kesikli ve sürekli rejim için hesaplamalar yapılmıştır. Çalışmada, konfor koşullarının PMV=0 olması durumunda enerji tüketimleri incelenerek iller arasındaki 1sıl konfor memnuniyeti ve enerji tüketiminindeki farklılıklar saptanmaya çalışılmıştır. PMV değerlerinin istatistiksel analizinde, İzmir ili için kesikli rejimde çalışmanın sürekli rejime göre daha iyi olmasına rağmen İstanbul için sürekli rejimde konfor koşulları açısından daha iyi sonuçlar alınmıștır. Tüm illerde sürekli rejim uygulandığında birim enerji tüketiminde artış olduğu belirlenmiştir. Sürekli rejim, kesikli rejime göre 1sitma enerji tüketiminde \% 4,5-6,2, soğutma enerji tüketiminde ise \% 9,1-23,2 daha yüksektir.

Anahtar Kelimeler: Is1l konfor, enerji tüketimi, klimatik zon, bina enerji performans1

\section{Assessment Of Building Energy Performance Depending On Thermal Comfort Temperatures At Turkey's Different Climate Conditions}

\begin{abstract}
Thermal comfort depends not only personal parameters such as the human physiology, age and gender but also environmental parameters. The operation mode of heating, cooling and air conditioning systems and outdoor temperatures are important parameters for thermal comfort. As a result of experimental studies, Fanger formed an indicator called the "Predicted Mean Vote (PMV) " and determined PMV=0 as the best value for comfort. In this study, first case building envelope properties were determined for four different cities representing four climatic regions of Turkey. Then thermal comfort temperatures were determined for each city and finally energy performance of the case buildings were evaluated based on these thermal comfort temperatures. The HVAC system was chosen as full mechanically controlled without allowing any personal intervention, analysed for both intermittent and continuous regimes. The study aims to exhibit user satisfaction and energy consumption change for each city when PMV=0. Statistical analysis of PMV values showed that although intermittent regime for Izmir gives lower energy consumption, continuous regime is better for Istanbul. For all cities, continuous regime consumes $4,5-6,2 \%$ more energy $\left(\mathrm{kWh} / \mathrm{m}^{2}\right)$ for heating, $9,1-23,2 \%$ for cooling comparing with intermittent regime.
\end{abstract}

Keywords: Thermal comfort, energy consumption, climatic zone, building energy performance

\footnotetext{
" Iletişim Yazarı

Geliş/Received $\quad: 9.12 .2020$

Kabul/Accepted $\quad: 12.03 .2021$

1 İzmir Yüksek Teknoloji Enstitüsü, Jeotermal Enerji Araştırma ve Uygulama Merkezi, Urla, İzmir, ebrukuzgunkaya@iyte.edu.tr, ORCID: 0000-0002-4574-6899

2 Yaşar Üniversitesi, Mühendislik Fakültesi, Makine Mühendisliği Bölümü, Bornova, İzmir, nurdan.yildirim@yasar.edu.tr, ORCID: 0000-0001-5140-6340

3 İzmir Yüksek Teknoloji Enstitüsü,Mühendislik Fakültesi, Enerji Sistemleri Mühendisliği Bölümü, 35430, Urla, İzmir, guldengokcen@iyte.edu.tr, ORCID: 0000-0002-3444-9610
} 


\section{EXTENDED ABSTRACT}

\section{Introduction}

The variables affecting thermal comfort can be classified as personal and environmental parameters. Heating and cooling energy needs; The climatic conditions depend heavily on the thermal comfort level as well as the building structure and type. Determining the relationship between thermal comfort and energy need / consumption is important in terms of both the calibration of energy classes according to the EU Directive 2018/844, as well as the ability to see the energy savings that can be made by those living in the space within the comfort temperature ranges, and to reveal the extra energy saving opportunities they can provide by changing their clothing and movement levels.

In this study; in accordance with TS 825, an exemplary housing in established criteria in TS 825 , selecting four cities representing different climatic regions of Turkey is designed. It is aimed to analyze the relationship between thermal comfort conditions and heating /cooling energy consumption in houses by determining the operative temperature ranges in accordance with EN 15251 for each province. For these temperature ranges, hourly PMV values and energy consumption seen throughout the year were determined by using one of the dynamic simulation methods according to ISO 13790. Considering the above working conditions, the thermal comfort conditions and energy consumption within the house throughout the year were determined and compared.

\section{Material}

Within the scope of this study, in order to determine the effect of thermal comfort conditions on heating and cooling energy consumption, a single storey detached house was designed.

EnergyPlus [1] software was used in modeling and simulating the house. DesignBuilder [2] is used in calculations as an Energy Plus [1] interface. Hourly meteorological data for İzmir, İstanbul and Ankara in Energy Plus [1] (epw) format are available in the database of the DesignBuilder software. Hourly data of Erzurum was taken from Meteonorm (v.5.1x, 2019) [3] in epw format and transferred to the DesignBuilder climate database.

\section{Method}

Example housing, for selected Izmir, Istanbul, Ankara and Erzurum in according to TS 825 representing Turkey in four different climatic regions, simulated monthly in EnergyPlus software by using with the full mechanically controlled HVAC systems where there is no natural ventilation.

In the fully mechanically controlled system where personal control is not allowed, the human body is more sensitive and the operating temperature set values used in the standards as comfort temperature are determined for the intermittent and continuous regime. Unit heating / cooling energy consumptions and primary energy consumptions that meet the thermal comfort conditions are calculated. For statistical evaluation, PMV values of the times the family stayed at home throughout the year were determined and evaluated using frequency distributions and distribution characteristics.

In the study, firstly, the monthly clo values to be used as input data in the simulation in determining the monthly operative set temperatures were determined for each province. The 
simulations were repeated using the determined set temperatures as input data to determine energy consumption and hourly PMV values.

Simulation results; 1) all day for energy consumption values, 2) for PMV values for the hours the family was in the house. The total number of simulations is approximately 864 .

\section{Results}

For PMV $=0$, operative set temperature ranges for the intermittent regime are determined to be $24.5-26.0^{\circ} \mathrm{C}$ in İzmir, 24.2-26.0 ${ }^{\circ} \mathrm{C}$ in Istanbul, 23.6-26.5 ${ }^{\circ} \mathrm{C}$ in Ankara and 23.3-26.4 ${ }^{\circ}$ $\mathrm{C}$ in Erzurum. In Izmir, where the outside temperature is the highest throughout the year, clo values are lower than other provinces. The operative temperatures required to provide comfort conditions are observed as the highest in Izmir in the winter months and the lowest in Istanbul in the summer months. The monthly single operative set temperature values obtained when the HVAC system is operated in continuous mode; $24.5-26.8^{\circ} \mathrm{C}$ in İzmir, $24.2-26.5^{\circ} \mathrm{C}$ in Istanbul, 23.7-26.9 ${ }^{\circ} \mathrm{C}$ in Ankara and $23.3-26.6^{\circ}$ in Erzurum As C, it was found approximately similar to the values obtained in the batch regime.

In the intermittent regime, although the input data is $\mathrm{PMV}=0$, there is a distribution in the range of 1.8 PMV for Erzurum. The larger the distribution range, the larger the standard deviation. $89.4 \%$ of the family's stay at home in Erzurum falls within the range of $-0.2<\mathrm{PMV}<+0.2$, which is the highest satisfaction level in the four thermal comfort categories, and $98.0 \%$ falls within the range of $-0.5<\mathrm{PMV}<+0.5$ which is the normal expectation level. Similar values were obtained for other provinces.

In continuous regime, PMV distribution is between 2.0 for İzmir and 1.1 PMV for Ankara. $89.9 \%$ of the time the family is at home in İzmir falls within the range of $-0.2<$ PMV $<+0.2$. This rate is $94.4 \%$ for the same PMV range in Istanbul, $94.3 \%$ in Ankara and $89.3 \%$ in Erzurum. In the range of $-0.5<\mathrm{PMV}<+0.5,98.5 \%$ of the hours spent at home in İzmir, $99.4 \%$ in Istanbul, 99.4\% in Ankara and Erzurum 98\% falls.

Although the operative temperature ranges for $\mathrm{PMV}=0$ are close to each other in all provinces, it is seen that heating / cooling energy consumption is different from each other. In the intermittent regime, heating energy consumption is highest in Erzurum and lowest in İzmir, while cooling energy consumption is the highest in İzmir and lowest in Erzurum. This reveals the effect of outdoor temperatures on energy consumption. When the intermittent regime and the continuous regime are compared, it is seen that the energy consumption values increase by $4.5-6.2 \%$ in heating and $9.3-24.1 \%$ in cooling. Cooling energy consumption increase is higher than heating. This increase is $18 \%$ and $23.2 \%$ in Ankara and Erzurum, respectively.

\section{Discussion and Suggestions}

The results obtained are summarized below:

While the monthly operative set temperatures determined in the intermittent regime are close to each other for İzmir $\left(24.5-26.0^{\circ} \mathrm{C}\right)$ and Istanbul $\left(24.2-26.0^{\circ} \mathrm{C}\right)$, in the same case it is observed in Ankara (23.6-26.5 ${ }^{\circ} \mathrm{C}$ ) and Erzurum (23.3-26.4 $\left.{ }^{\circ} \mathrm{C}\right)$. In the continuous regime, although there is no big difference in temperatures for the winter season, there is an increase in summer temperatures in İzmir $\left(24.5-26.8^{\circ} \mathrm{C}\right)$ and Istanbul $\left(24.2-26.5^{\circ} \mathrm{C}\right)$.

Annual unit heating / cooling energy consumptions obtained for operative set temperatures providing PMV $=0$ have been compared. It has been determined that there is an increase in unit 
energy consumption when the continuous regime is applied. Continuous regime is $4.5-6.2 \%$ higher in heating energy consumption and $9.1-23.2 \%$ higher in cooling energy consumption compared to intermittent regime. The highest increase in cooling energy consumption and the lowest increase in heating energy consumption is in Erzurum.

In the statistical analysis of hourly PMV values obtained from the simulations using the operative temperatures that make PMV $=0$ as input data, working in the intermittent regime for the province of Izmir is $0.4 \%$ in the comfort range of $-0.5<\mathrm{PMV}<+0.5$ according to the continuous regime. It is seen that it gives $4.3 \%$ better results in the range of $-0.2<\mathrm{PMV}<+0.2$. Considering the calculations made in continuous regime for Istanbul, higher values in both -0.2 $<$ PMV $<+0.2$ comfort range $(5.2 \%)$ and $0.5<$ PMV $<+0.5$ comfort range $(0.6 \%)$ was seen. In the intermittent regime comfort range of $-0.2<\mathrm{PMV}<+0.2$, Ankara and Erzurum provinces $0.1-0.2 \%$ and in continuous regime $-0.5<\mathrm{PMV}<+0.5$ comfort interval Ankara province $0.4 \%$ more results in more satisfaction.

In all the working regimes and control strategies examined, it has been observed that as the outdoor temperatures decrease, the change in energy consumption is greater and the most dramatic changes occur in Erzurum.

In this study, in which the comfort conditions to be obtained in various working regimes and HVAC control strategies and energy consumption are compared; We believe that it will guide the architects and engineers who design and install houses, as well as to show the current energy saving potential in preferred comfort conditions and to evaluate energy consumption together with comfort conditions.

\section{References}

1. EnergyPlus Engineering Reference. 2019. The Reference to EnergyPlus Calculations. https://energyplus.net/sites/all/modules/custom/nrel_custom/pdfs/pdfs_v8.9.0/ EngineeringReference.pdf

2. Design Builder Software. 2020. http://www.designbuilder.co.uk.

3. METEONORM. 2020. Global Meteorological Database for Engineers, Planners and Education, www.meteonorm.com. 


\section{GIRIŞ}

Isıl konfor terimi, insanın bulunduğu ortamın ısıl koşullarını ne daha sıcak ne de daha soğuk istememesi halidir. İnsanın yapısı, yaşı, cinsiyeti gibi birçok parametreye bağlı olsa bile en genel anlamda 1sıl konforu etkileyen değişkenler kişisel ve çevresel parametreler olarak sınıflandırılabilir. Kişisel parametreler, aktivite seviyesi (met) ve k1yafetin isıl direnci (clo) olmak üzere iki ana paramete ile ilişkilidir. Çevresel parametreler ise hava sıcaklığı, ortalama radyasyon sıcaklığı, hava hızı ve bağıl nemdir [1].

Fanger [1], çok sayıda bireyden oluşan bir topluluk için en az \%80'lik memnuniyeti sağlayacak konfor sıcaklığını kontrollu olarak iklimlendirilmiş bir ortamda tahmin etmeye çalışmıştır. Deneysel çalışmalar sonucu "tahmini ortalama oy" (PMV) olarak adlandırılan bir gösterge oluşturmuş, konfor bölgesi için +1 , $0,-1$ oylarını konforlu olarak nitelendirmiştir. PMV=0'ın anlamı vücudun 1sı kaybı ile üretilen metabolik 1sının eşit olmasıdır. Isıl konfor seviyesinin sınıflandırılması ve sertifikasyonu EN 15251 [2] standardı tarafindan yapılmaktadır. Bu standart, HVAC sistem tasarımında kullanılacak ısıl konfor parametrelerinin belirlenmesinin yanısıra ölçüm ve hesaplamalardan kaynaklanan uzun vadeli ısıl konfor değerlendirme metodlarını da tanımlar. EN 15251 [2]'de binalar, ısıl konfor PMV indeksine göre sınıflandırılmıştır. Isıl konfor seviyesi 3 kategoride sınıflandırılır: I. kategori, ısıl konfor açısından en yüksek beklenti seviyesini, dolayısı ile en yüksek memnuniyet seviyesini $(-0,2<\mathrm{PMV}<+0,2)$ gösterir. Engelli, hasta kişiler, yaşlılar ve çocukların bulunduğu hacimler için tavsiye edilir. II. kategori, yeni ve tadilat görmüş binalar için kullanılır ve normal beklenti seviyesine karşılık gelir. Bu kategori için $-0,5<\mathrm{PMV}<+0,5$ aralığı önerilir ki standardlarda ve uygulamalarda yaygın olarak kullanılan ısıl konfor aralığıdır. III. kategoride ortamda bulunan memnuniyetsiz kişilerin oranının \%15'u aşmaması için $-0,7<\mathrm{PMV}<+0,7$ aralığı gerekliliği belirtilmiştir [1, 3-7].

Hava sıcaklığı, hava bağıl nemi, hava hızı, hacmi çevreleyen yüzeyler ile hacim içinde yer alan objelerin yüzey sıcaklıkları (ortalama radyasyon sıcaklığı) konfor koşullarına birlikte etki etmektedir. Bina kabuğu güneş radyasyonuna maruz ise iç ortam hava sıcaklığı ile nem kontrolü konfor koşullarını garanti edemediğinden ortalama radyasyon sıcaklığı önemli bir faktör haline gelmektedir. Bir hacimde yüzeyler ve objeler soğuk ise hava sıcaklığı yeterli olsa bile soğuk hissedilebilir. Yüzeylerin sıcaklığı, bina kabuğunun yalıtımı ile doğrudan ilişkilidir [8]. Isıl konfor hesaplamalarında kullanılan operatif sıcaklık; hava sıcaklığı ile ortalama radyasyon sıcaklığının kombinasyonundan oluşmaktadır [1, 3, 9]. ANSI/ASHRAE 55 [9] ve EN ISO 7730 [3]'te 1sıl konfor sıcaklığı olarak "operatif sıcaklık” değerlerinin kullanılmasının sebebi, insan vücudunun operatif sıcaklığa karşı daha duyarlı olmasıdır.

Ekonomik ve sosyal açıdan dünya yaşam standartlarını ve ülkelerin gelişmişlik seviyesinde iyileşme sağlayan en önemli faktörlerin başında enerji gelmektedir. Sanayi- 
deki ve teknolojideki büyük gelişmeler ve değişimler, artan nüfus ile birlikte enerjiye olan ihtiyaç sürekli artış göstermektedir. Dünya birincil enerji tüketiminin 2015 yılında yaklaşık \%81,6'sı petrol, kömür ve doğalgazdan sağlanmaktadır [10]. Enerjinin çoğunlukla rezervleri giderek azalan fosil yakıtlardan karşılanıyor olması, enerji ihtiyacının sürekli artması enerji verimliliği ve yenilenebilir enerji kaynaklarının kullanımının çok daha önemli kılmaktadır.

Global enerji tüketiminin yaklaşı1k \%10’u konutlarda olmaktadır [10]. Konutlarda enerji kullanımında en büyük paya sahip olan ısıtma ve soğutma enerji ihtiyacı; iklimsel koşullar, bina yapı özellikleri ve tipinin yanı sıra ısıl konfor düzeyine önemli ölçüde bağlıdır. Isıl konfor ve enerji ihtiyacı/tüketimi arasındaki ilişkinin belirlenmesi hem EU Directive 2018/844 [11] göre enerji sınıflarının kalibrasyonu hem de hacim içinde yaşayanların konfor sıcaklığı aralıklarında yapabilecekleri enerji tasarrufunu görebilmeleri, giyim ve hareket düzeylerini değiştirmeleri ile sağlayabilecekleri ekstra enerji tasarrufu olanaklarının ortaya konması açısından önemlidir.

Binalarda enerji performansının belirlenmesi; binada ısıl konfor ve iç hava kalitesini sağlayan sistemlerin, değişen dış hava koşullarına göre zamana bağlı (transient) davranışının simülasyonu ile gerçekleştirilir. Ancak zamana bağlı enerji tüketim simülasyonları, uzmanlık gerektiren, karmaşık hesaplamalardır. Pratik anlamda, gelişmiş bilgisayar yazılımları kullanılmadan binaların dinamik hesaplamalarının yapılması mümkün değildir. ISO 13790 [12]'da statik ve dinamik hesap yöntemleri verilmiştir. Dinamik metodlar saatlik bazda iç ve dış hava sıcaklıkları kullanılarak binalardaki enerji transferinin anlık simülasyonuna yaklaşan kompleks metodlardır.

Binalarda enerji verimliliği, enerji performansı ile konfor seviyesinin ilişkilendirilmesi üzerine yapılmış pek çok çalışma mevcuttur [4, 5, 13-35]. Türkiye'de TS 825 [36]'in zorunlu hale gelmesi ile binalarda enerji performansı çalışmaları başlamıştır [37-44].

Bu çalışmada; TS 825 [36]'de Türkiye'nin farklı iklim bölgelerini temsil eden dört il seçilerek, TS 825 [36]'de belirlenmiş kriterlere uygun örnek bir konut tasarlanmıştır. Her il için EN 15251 [2]'e uygun operatif sıcaklık aralıkları belirlenerek, konutlarda 1sıl konfor koşulları ile 1sıtma/soğutma enerji tüketimleri arasındaki ilişkinin analiz edilmesi hedeflenmiştir. Bu sıcaklık aralıkları için ISO 13790 [12]'a göre dinamik simülasyon yöntemlerinden biri kullanılarak yıl boyunca görülen saatlik PMV değerleri ve enerji tüketimleri belirlenmiştir. Simülasyonlarda tam mekanik kontrol sistemi kullanılmıştır. Tam mekanik kontrol için Fanger 1sıl konfor modeli yaklaşımı kullanılmıştır. Tam mekanik kontrollu sistemde kesikli ve sürekli çalışma rejimleri altında çalışılan aylık tek 1sıtma/soğutma operatif sıcaklık set değerleri kullanılmıştır. Yukarıdaki çalışma koşulları gözönünde bulundurularak konut içerisinde yıl boyunca gerçekleşen 1sıl konfor koşulları ve enerji tüketimleri belirlenmiş ve karşılaştırılmıştır. 


\section{MATERYAL}

Bu çalışma kapsamında, 1sıl konfor koşullarının ısıtma ve soğutma enerji tüketimlerine olan etkisinin belirlenmesi amacıyla tek katlı ayrı nizamda örnek bir konut tasarlanmıştır. Konutun dış görünümü ve iç yerleşim planı Şekil 1'de gösterilmektedir. Konutun oturma alanı $100 \mathrm{~m}^{2}$ olup duvar, pencere, kapı gibi bileşenlerinin boyutları ve alanları Tablo 1'de verilmiştir [43]. Pencere/duvar oranı 0,187 olarak alınmıştır. Tablo 3 'te, konutu oluşturan duvar, taban ve tavan gibi opak yapı elemanların kalınlıkları ve termofiziksel özellikleri listelenmiştir. Tasarımda, pencerelerde $4 \mathrm{~cm}$ kalınlığında PVC çerçeve, $3 \mathrm{~mm}$ cam kalınlığında ve $13 \mathrm{~mm}$ hava boşluklu çift cam kullanılımıştır [43].

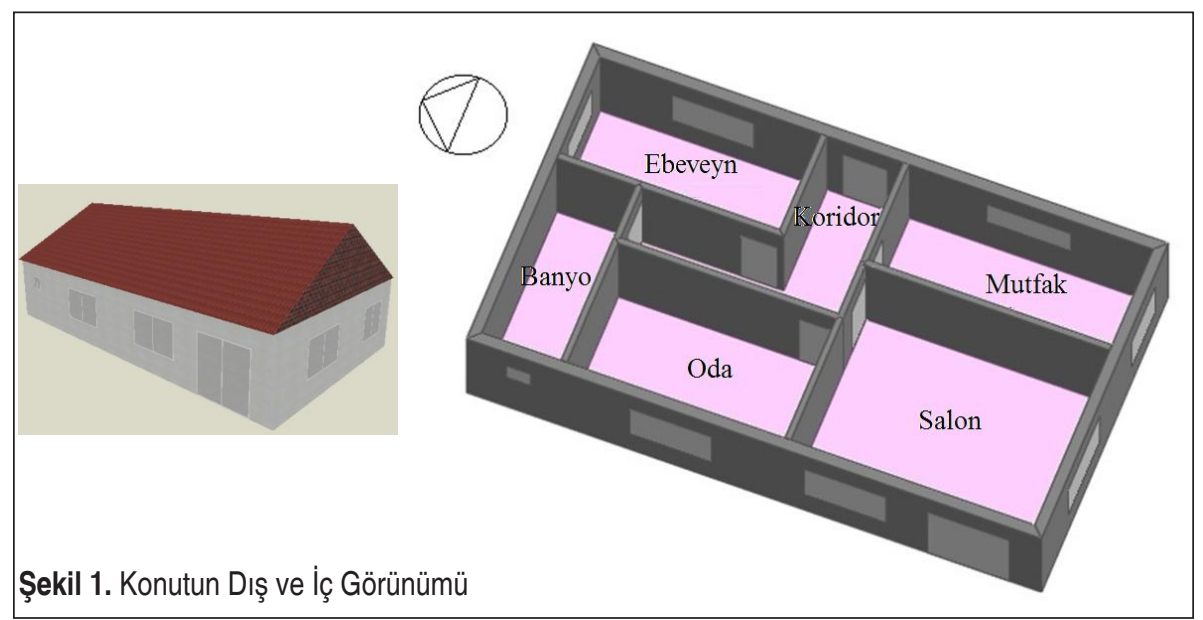

Tablo 1. Konutun Bileşenlerinin Alanları $\left(\mathrm{m}^{2}\right)$

\begin{tabular}{|l|c|c|c|c|c|c|}
\hline \multirow{2}{*}{ Mahal } & Yön & Pencere & Kapı & Dış duvar & Taban & Tavan \\
\hline \multirow{2}{*}{ Ebeveyn yatak odası } & $\mathrm{G}$ & 2,6 & - & 10,6 & 28,85 & 28,85 \\
\cline { 2 - 7 } & $\mathrm{B}$ & 2,6 & 4,2 & 9,73 & & \\
\cline { 2 - 7 } & $\mathrm{K}$ & 1,89 & - & 5,43 & 14,5 & 14,5 \\
\hline \multirow{2}{*}{ Yatak odası } & $\mathrm{D}$ & 2,6 & - & 12,39 & & \\
\hline \multirow{2}{*}{ Mutfak } & $\mathrm{B}$ & 2,6 & - & 12,39 & 17,99 & 17,99 \\
\hline \multirow{2}{*}{ Banyo } & $\mathrm{G}$ & 1,95 & - & 5,37 & 15,99 & 15,99 \\
\cline { 2 - 7 } & $\mathrm{D}$ & 1,85 & - & 14,73 & & \\
\hline Koridor & $\mathrm{K}$ & - & - & 13,2 & 9,6 & 9,6 \\
\hline \multirow{2}{*}{ TOPLAM ALAN } & $\mathrm{B}$ & 0,36 & - & 5,14 & & \\
\hline
\end{tabular}


Örnek konutun inceleneceği farklı iklim koşulları için TS 825 [36]'de belirlenen 4 farklı iklim bölgesini temsil eden İzmir (I. Bölge), İstanbul (II. Bölge), Ankara (III. Bölge) ve Erzurum (IV. Bölge) illeri seçilmiştir. Bu dört farklı ilde konutun, TS 825 [36]'e göre minimum koşulları sağlaması için yapı elemanlarının sahip olması gereken toplam ısı geçiş kaysayısını (U) (Tablo 3) sağlayacak farklı yalıtım kalınlıkları (Tablo 2'deki X değerleri) ve her bir il için bu yalıtım kalınlıkları kullanılarak hesaplanan U değerleri Tablo 3'de verilmiştir.

Örnek konut 4 kişilik bir aileye göre tasarlanmış ve kesikli çalışma durumunda ailenin konutta bulunduğu saatler hafta içi ve hafta sonu olmak üzere ayrı ayrı ele alınmıştır (Tablo 4) [43].

Çalışmada, HVAC sistemi hem kesikli hem de sürekli çalışma rejiminde değerlendirilmiştir. Isıtma sistemi olarak, doğal gaz yakıtlı kazan ve sıcak sulu radyatör sistemi, soğutma sistemi olarak da klima kullanımı öngörülmüştür. Isıtma sistem verimi $\% 85$, soğutma sistemi COP değeri 3 olarak alınmıştır.

Tablo 2. Örnek Konut Opak Yapı Elemanları Termofiziksel Özellikleri

\begin{tabular}{|c|c|c|c|c|}
\hline & $\begin{array}{l}\text { Yapı elemanı } \\
\text { kalınlığı } \\
(\mathrm{m})\end{array}$ & $\begin{array}{l}\text { Isı iletim } \\
\text { katsayısı } \\
(\mathrm{W} / \mathrm{mK})\end{array}$ & $\begin{array}{l}\text { Yoğunluk } \\
\left(\mathrm{kg} / \mathrm{m}^{3}\right)\end{array}$ & $\begin{array}{l}\text { Isı kapasitesi } \\
(\mathrm{J} / \mathrm{kgK})\end{array}$ \\
\hline \multicolumn{5}{|l|}{ Dış duvar } \\
\hline Çimento harçlı şap & 0,015 & 1,4 & 2000 & 840 \\
\hline XPS yalıtım malzemesi & $x$ & 0,04 & 30 & 840 \\
\hline Düşey delikli tuğla & 0,19 & 0,68 & 1600 & 800 \\
\hline Çimento harçlı şap & 0,015 & 1,4 & 2000 & 840 \\
\hline \multicolumn{5}{|l|}{ Tavan } \\
\hline Çimento harçlı şap & 0,015 & 1,4 & 2000 & 840 \\
\hline Cam yünü & $x$ & 0,04 & 30 & 840 \\
\hline Donatılı beton & 0,15 & 2,3 & 2300 & 1000 \\
\hline Çimento harçlı şap & 0,015 & 1,4 & 2000 & 840 \\
\hline \multicolumn{5}{|l|}{ Taban } \\
\hline Çimento harçlı şap & 0,02 & 1,4 & 2000 & 840 \\
\hline Cam yünü & $x$ & 0,04 & 30 & 840 \\
\hline Çimento harçlı şap & 0,02 & 1,4 & 2000 & 840 \\
\hline Donatılı beton & 0,20 & 2,3 & 2300 & 1000 \\
\hline Kum-Çakıl & 0,10 & 2,0 & 1900 & 880 \\
\hline
\end{tabular}


Tablo 3. Örnek Konutun Illere Göre Yalıtım Kalınlıkları (Tablo 3'deki X değerleri) ve Toplam Isı Geçiş Katsayısı (U) (W/m²K) Değerleri [43]

\begin{tabular}{|c|c|c|c|c|c|c|c|}
\hline \multirow{3}{*}{ Şehirler } & \multicolumn{2}{|c|}{ Dış Duvar } & \multicolumn{2}{|c|}{ Tavan } & \multicolumn{2}{|c|}{ Taban } & \multirow{2}{*}{\begin{tabular}{|l} 
Pencere \\
$\mathbf{U}_{\text {Pencere }}$
\end{tabular}} \\
\hline & $\begin{array}{l}\text { İzolasyon } \\
\text { Kalınlığı } \\
(X)\end{array}$ & $U_{\text {Duvar }}$ & $\begin{array}{l}\text { İzolasyon } \\
\text { Kalınlığı } \\
\text { (X) }\end{array}$ & $\mathrm{U}_{\text {Tavan }}$ & $\begin{array}{l}\text { İzolasyon } \\
\text { Kalınlığı } \\
(X)\end{array}$ & $U_{\text {taban }}$ & \\
\hline & $(\mathrm{cm})$ & $\left(\mathrm{W} / \mathrm{m}^{2} \mathrm{~K}\right)$ & $(\mathrm{cm})$ & $\left(\mathrm{W} / \mathrm{m}^{2} \mathrm{~K}\right)$ & $(\mathrm{cm})$ & $\left(\mathrm{W} / \mathrm{m}^{2} \mathrm{~K}\right)$ & $\left(\mathrm{W} / \mathrm{m}^{2} \mathrm{~K}\right)$ \\
\hline İzmir (1. Bölge) & 5 & 0,581 & 8 & 0,447 & 5 & 0,615 & 2,282 \\
\hline İstanbul (2. Bölge) & 8 & 0,405 & 10 & 0,365 & 8 & 0,421 & 2,282 \\
\hline Ankara (3. Bölge) & 10 & 0,337 & 14 & 0,268 & 10 & 0,348 & 2,282 \\
\hline Erzurum (4. Bölge) & 12 & 0,288 & 15 & 0,251 & 12 & 0,296 & 2,282 \\
\hline
\end{tabular}

Tablo 4. Ailenin Konutta Bulunduğu Saatler

\begin{tabular}{|c|c|}
\hline \multicolumn{2}{|c|}{ Ailenin konutta bulunduğu saatler } \\
\hline Hafta içi & Hafta sonu \\
\hline $18: 00-08: 00$ & Tüm gün \\
\hline $18: 00-08: 00$ & Tüm gün \\
\hline $17: 00-08: 00$ & Tüm gün \\
\hline $18: 00-24: 00$ & $11: 00-24: 00$ \\
\hline
\end{tabular}

Konutun modellenmesi ve simüle edilmesinde EnergyPlus [45] yazılımı kullanılmıştır. EnergyPlus [45], DOE-2 ve BLAST programları temel alınarak ABD Enerji Bakanlığı tarafından geliştirilmiş, yüksek hesaplama kapasiteli bir bina enerji simülasyon programıdır [46]. Saatlik-dinamik bir metot olan ASHRAE [47] Isıl Denge Metodu'nu kullanan yazılım, hassas ve detaylı bir çizim modeli oluşturmaya olanak sağlar ve dolayısıyla yapılması gerekli kabul sayısını da en aza çekerek gerçeğe çok yakın hesaplamalar yapar. Yazılım, güneş kazançlarını ve iç kazançların detaylı hesaplanmasını, iç yüzey sıcaklıklarının her yüzey için ayrı ayrı tanımlanmasını, doğal havalandırmayı, gölgelenmeyi, HVAC ekipmanlarını ve ısıl kütle hesaplamalarını da hesaba katmaktadır [45, 47-49]. EnergyPlus [45], ANSI/ASHRAE 140 [49] doğrulamasına sahiptir.

DesignBuilder [50], bir Energy Plus [45] ara yüzeyi olarak hesaplamalarda kullanılmaktadır. DesignBuilder yazılımının veritabanında Energy Plus [44] (epw) formatında İzmir, İstanbul ve Ankara için saatlik meteorolojik veriler mevcuttur. Erzurum'a ait saatlik veriler ise Meteonorm (v.5.1x, 2019) [51] yazılımından epw formatında alınarak DesignBuilder iklim veritabanına aktarılmıştır. 


\section{YÖNTEM}

Örnek konut, TS 825 [36]'de belirlenen Türkiye'nin dört farklı iklim bölgesini temsilen seçilen İzmir (I. Bölge), İstanbul (II. Bölge), Ankara (III. Bölge) ve Erzurum (IV. Bölge) için aynı ısıtma/soğutma sistemi, kullanım süresi ile kesikli ve sürekli çalışma rejimi benimsenerek EnergyPlus yazılımında aylık olarak simüle edilmiştir.

$\mathrm{Bu}$ çalışmanın ilk adımı; seçilen her bir il için simülasyonlarda giriş verisi olarak kullanılacak olan aylık clo değerlerini, aylık ortalama dış hava sıcaklığının bir fonksiyonu olarak belirlemektir. Isıl konfor için kişisel parametre olan ve kişilerin giyinme durumunu gösteren clo değeri dış iklimsel verilere bağlı olarak değişmektedir. Isıtma ve soğutma enerji tüketimleri de kişilerin giyinme durumuna göre değişiklik gösterir. Clo değerleri, yıl içinde $\leq 1,2$ met (aktivite seviyesi) $\% 50$ bağıl nem ve $\leq 0,15 \mathrm{~m} / \mathrm{s}$ hava hızı için 0,5 (yaz)-1,0 (kış) arasında değişir. Toplam clo değeri, üstüste giyilen herbir kıyafetin clo değerlerinin toplamına eşittir [9]. Clo değerinin belirlenmesinde dış hava sıcaklığı önemli bir parametredir.

Tablo 5. Aylık Ortalama Dış Hava Sıcaklıkları

\begin{tabular}{|l|c|c|c|c|c|c|c|c|c|c|c|c|}
\hline & Oca. & Şub. & Mar. & Nis. & May. & Haz. & Tem. & Ağu. & Eyl. & Eki. & Kas. & Ara. \\
\hline İzmir & 8,9 & 8,4 & 10,7 & 14,4 & 21,0 & 24,4 & 25,8 & 25,4 & 23,0 & 17,0 & 11,4 & 9,8 \\
\hline İstanbul & 5,8 & 4,9 & 7,3 & 12,2 & 16,8 & 21,6 & 24,1 & 24,2 & 20,8 & 16,5 & 11,4 & 7,9 \\
\hline Ankara & $-2,4$ & 0,6 & 2,6 & 8,9 & 13,7 & 17,0 & 21,5 & 21,1 & 17,1 & 10,3 & 3,8 & 0,8 \\
\hline Erzurum & $-7,0$ & $-6,5$ & $-1,7$ & 5,7 & 10,8 & 15,1 & 19,5 & 18,9 & 15,0 & 9,0 & 1,6 & $-4,4$ \\
\hline
\end{tabular}

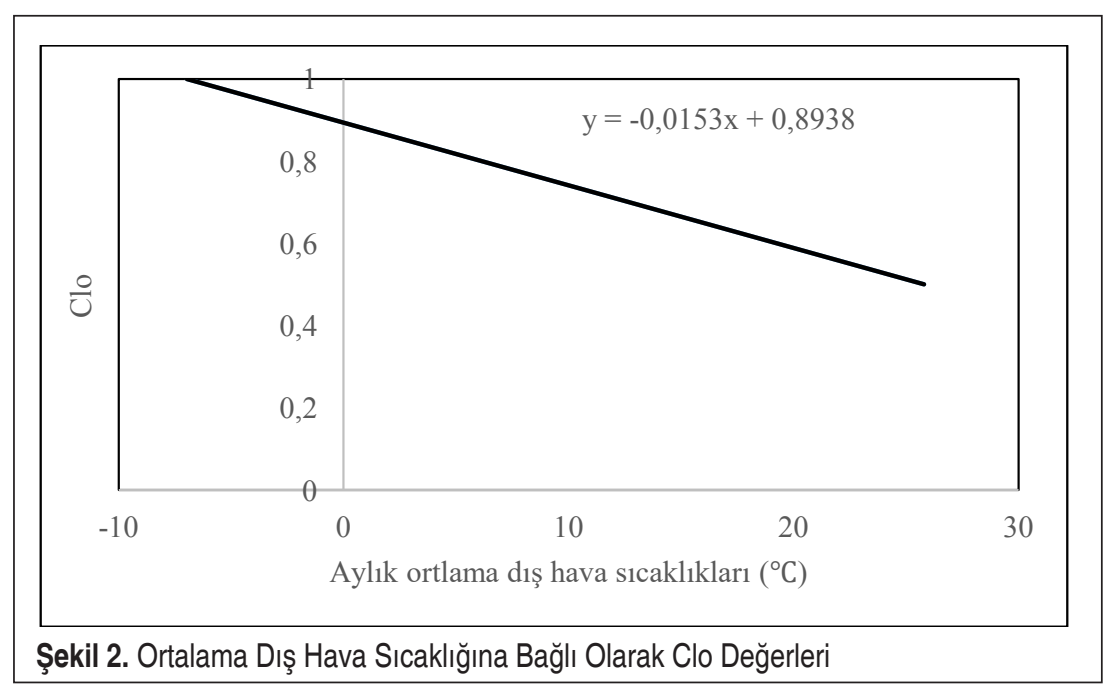


İzmir, İstanbul, Ankara ve Erzurum illerinin ortalama dış hava sıcaklıkları Tablo 5 'te verilmiştir. Clo değerinin dış hava sıcaklığı ile lineer değiştiği kabulü ile [4] Şekil 2 elde edilmiştir. Sıcaklığa bağlı clo fonsiyonu ise Eşitlik 1'de verilmiştir.

clo $=-0,0153 * \mathrm{~T}_{\mathrm{o}}+0,8938$

burada; $\mathrm{T}_{\mathrm{o}}$ : dış hava sıcaklığ ${ }^{\circ}\left({ }^{\circ} \mathrm{C}\right)$ 'dır.

Sıcaklık set değerlerinin belirlenmesi için konut, ısıtma ve soğutma operatif sıcaklık değerlerinde $1^{\circ} \mathrm{C}$ 'lik sıcaklık değişimi için simüle edilmiş ve aylık ortalama PMV değerleri belirlenmiştir. Isıtma ve soğutma operatif sıcaklık değerleri, ANSI/ASHRAE 55 [9] ve ISO 7730 [3]' da verilen $19,0-26,5^{\circ} \mathrm{C}$ ssitma ve $23,5-28,0^{\circ} \mathrm{C}$ soğutma sicaklık aralıklarında alınmıştır. Set sıcaklık değerleri ile aylık ortalama PMV değerleri lineer olarak değiştiğinden, $-0,5<\mathrm{PMV}<+0,5$ konfor aralığında PMV'yi $-0,5,0$ ve $+0,5$ yapan aylık sıcaklık (operatif) set değerlerini belirlemek amacıyla, set sıcaklığı-PMV eğrileri oluşturulmuştur.

Saatlik PMV değerlerinin belirlenmesi için PMV=0 yapan set sıcaklıkları simülasyonlarda giriş verisi olarak kullanılmıştır. Çıkış verisi ise ailenin konutta bulunduğu saatler için çalıştırılan simülasyonlardan elde edilen saatlik PMV değerleridir. Yı1 boyunca elde edilen saatlik PMV değerlerinin istatistiksel olarak değerlendirilmesi yapılmıştır. Frekans dağılımları ve dağılım özellikleri (ortalama değer, orta değer, standard sapma, varyans, en küçük değer, en büyük değer ve aralık), veriyi gruplara ayırarak anlaşılabilir hale getirmek ve gözlenme sıklıklarını ve olasılıklarını belirlemek için uygulanmıştır. İstatistiksel veriler yardımıyla, ailenin konutta bulunduğu saatlerdeki konfor aralıkları incelenmiş ve $-0,2<\mathrm{PMV}<+0,2$ ve $-0,5<\mathrm{PMV}<+0,5$ konfor aralıklarındaki yüzdeleri belirlenmiştir.

Birim enerji tüketim değerlerinin belirlenmesi amacıyla bir yıl için PMV=0 yapan operatif sıcaklık set değerleri kullanılarak konutun aylık 1sıtma/soğutma birim enerji tüketim $\left(\mathrm{kWh} / \mathrm{m}^{2}\right)$ değerleri elde edilmiştir. Aynı zamanda, konutta tüketilen her bir enerji türüne (doğalgaz, elektrik) göre yıllık birincil enerji tüketimi değerleri hesaplanmıştır. Birincil enerji dönüşüm katsayıları doğalgaz yıllık enerji tüketimi 1,0, elektrik yıllık enerji tüketimi ise 2,36 ile çarpılarak yıllık toplam birincil enerji tüketimi hesaplanmıştır [52, 53].

\section{SONUÇLAR}

Örnek konut, TS 825 [36]'de belirlenen Türkiye'nin dört farklı iklim bölgesini temsilen seçilen İzmir (I. Bölge), İstanbul (II. Bölge), Ankara (III. Bölge) ve Erzurum (IV. Bölge) için doğal havalandırmanın olmadığı tam mekanik kontrollu HVAC sisteminin, aylık tek 1sıtma/soğutma operatif sıcaklık set değeri ile kullanım süresi ve 
çalışma rejimi (kesikli-sürekli) benimsenerek EnergyPlus yazılımında aylık olarak simüle edilmiştir.

Kişisel kontrole izin verilmeyen tam mekanik kontrollu sistemde insan vücudunun daha hassas olduğu ve konfor sıcaklığı olarak standardlarda kullanılan operatif s1caklık set değerleri kesikli ve sürekli rejim için belirlenmiştir. Isıl konfor koşullarını sağlayan birim 1sıtma/soğutma enerji tüketimleri, birincil enerji tüketimleri hesaplanmıştır. İstatistiksel açıdan değerlendirmeiçin ise ailenin yıl boyunca evde bulunduğu saatlere ait PMV değerleri saptanmış, frekans dağılımları ve dağılım özellikleri kullanılarak değerlendirilmiştir.

Çalışmada ilk olarak aylık operatif set sıcaklıklarının belirlenmesinde simülasyonda giriş verisi olarak kullanılacak olan aylık clo değerleri her il için belirlenmiştir. Belirlenen set sıcaklıkları enerji tüketimi ve saatlik PMV değerlerinin belirlenmesi amacıyla giriş verisi olarak kullanılarak simülasyonlar tekrarlanmıştır.

Simülasyon sonuçları; 1) enerji tüketim değerleri için tüm gün, 2) PMV değerleri için ailenin konutta bulunduğu saatler için alınmıştır. Toplam simülasyon sayısı yaklaşık 864'tür.

Hesaplamalarda, 1sıtma/soğutma enerji tüketiminin belirlenmesinde doğalgaz ile klimaların elektrik tüketimi dikkate alınmış, fan, pompa vb. yardımcı ekipmanların tüketimi elektrik tüketimine dahil edilmemiştir. Sıcak su ve aydınlatma enerji tüketimleri çalışmada dikkate alınmamış, sadece 1sıtma ve soğutma enerji tüketimleri incelenmiştir. İç 1sı kazançları TS EN 832 [54]'ye göre konut ortalaması 5 W/m² olacak şekilde belirlenmiştir. İç 1sı kazançları olarak, ailenin konutta bulunma durumuna bağlı olarak değişen metabolik kazançlar, cihaz kullanımı ve aydınlatmadan kaynaklanan kazançlar ele alınmıştır. Çalışmada, ısıl konforu etkileyen iç mekan iklimsel parametrelerinden olan hava hızı $0,1 \mathrm{~m} / \mathrm{s}$ 'den düşük olarak kabul edilmiş, kişisel parametrelerden olan konut içindeki aktivite seviyesi ise 0,9 met olarak sabit tutulmuştur.

Seçilen her il için aylık clo değerleri, aylık ortalama dış hava sıcaklığının bir fonksiyonu olarak belirlenmiş ve Eşitlik 1'de verilmiştir. Tablo 5'de listelenen ortalama diş hava sıcaklıkları Eşitlik 1'de yerine konarak her il için aylık clo değerleri belirlenmiş

Tablo 6. Aylık Clo Değerleri

\begin{tabular}{|l|l|l|l|l|l|l|l|l|l|l|l|l|}
\hline & Oca. & Şub. & Mar. & Nis. & May. & Haz. & Tem. & Ağu. & Eyl. & Eki. & Kas. & Ara. \\
\hline İzmir & 0,76 & 0,77 & 0,73 & 0,67 & 0,57 & 0,52 & 0,50 & 0,51 & 0,54 & 0,63 & 0,72 & 0,74 \\
\hline İstanbul & 0,81 & 0,82 & 0,78 & 0,71 & 0,64 & 0,56 & 0,53 & 0,52 & 0,58 & 0,64 & 0,72 & 0,77 \\
\hline Ankara & 0,93 & 0,89 & 0,85 & 0,76 & 0,68 & 0,63 & 0,56 & 0,57 & 0,63 & 0,74 & 0,84 & 0,88 \\
\hline Erzurum & 1,00 & 0,99 & 0,92 & 0,81 & 0,73 & 0,66 & 0,60 & 0,60 & 0,66 & 0,76 & 0,87 & 0,96 \\
\hline
\end{tabular}




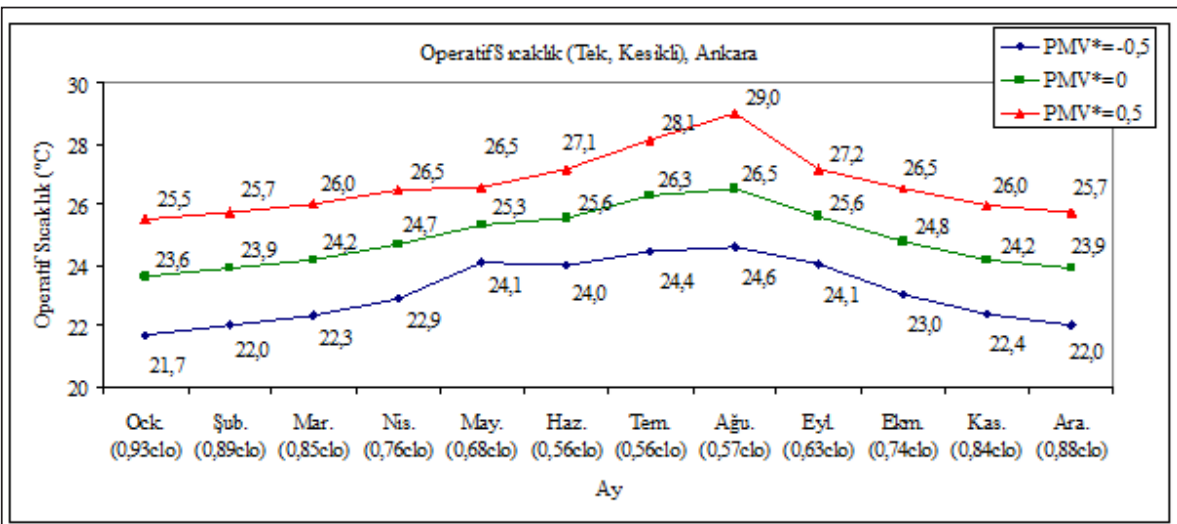

Şekil 3. Kesikli Çalışma Durumunda Operatif Sıcaklık Set Değerleri (Ankara)

ve Tablo 6'de sunulmuştur. Aylık ortalama dış hava sıcaklığı arttıkça insanlar daha hafif giysiler giymekte, clo değeri düşmektedir.

Belirlenen aylık clo değerleri kullanılarak ANSI/ASHRAE Standard 55 [9] ve ISO 7730 [3]'da verilen $19,0-26,5^{\circ} \mathrm{C}$ 1sitma, $23,5-28,0^{\circ} \mathrm{C}$ soğutma operatif sicaklık aralıkları için $1^{\circ} \mathrm{C}$ 'lik sıcaklık adımlarında İzmir, İstanbul, Ankara ve Erzurum illeri için kesikli ve sürekli rejimde konut simüle edilmiş ve $-0,5<\mathrm{PMV}<+0,5$ konfor aralığında $P M V=-0,5,0$ ve $+0,5$ 'i sağlayan aylık tek operatif sıcaklık set değerleri belirlenmiştir. Şekil 3'de örnek olarak Ankara ili için HVAC sisteminin kesikli rejimde çalışması durumu için elde edilen aylık tek operatif set sıcaklık değerleri gösterilmekte olup, tüm iller için $\mathrm{PMV=0}$ yapan operatif set sıcaklık değerleri, kesikli ve sürekli rejimler için Tablo 7'de verilmektedir.

Tablo 7. Tüm İller İçin Elde Edilen Pmv=0 Yapan Operatif Set Sıcaklık Değerleri

\begin{tabular}{|l|l|l|l|l|l|l|l|l|l|l|l|l|l|}
\hline Rejim & il & Oca. & Şub. & Mar. & Nis. & May. & Haz. & Tem. & Ağu. & Eyl. & Eki. & Kas. & Ara. \\
\hline \multirow{4}{*}{ Kesikli } & İzmir & 24,5 & 24,5 & 24,6 & 24,9 & 25,7 & 25,9 & 26,0 & 26,0 & 26,0 & 25,5 & 24,7 & 24,6 \\
\cline { 2 - 12 } & İstanbul & 24,2 & 24,2 & 24,4 & 24,8 & 25,3 & 26,0 & 25,7 & 25,7 & 25,6 & 25,4 & 24,7 & 24,4 \\
\cline { 2 - 13 } & Ankara & 23,6 & 23,9 & 24,2 & 24,7 & 25,3 & 25,6 & 26,3 & 26,5 & 25,6 & 24,8 & 24,2 & 23,9 \\
\cline { 2 - 12 } & Erzurum & 23,3 & 23,4 & 23,8 & 24,4 & 25,3 & 25,4 & 26,4 & 26,2 & 25,4 & 24,6 & 24,1 & 23,6 \\
\hline \multirow{4}{*}{ Sürekli } & İzir & 24,5 & 24,5 & 24,7 & 24,8 & 25,8 & 26,8 & 26,4 & 26,2 & 25,9 & 24,9 & 24,8 & 24,2 \\
\cline { 2 - 12 } & İstanbul & 24,2 & 24,2 & 24,4 & 24,8 & 25,3 & 26,5 & 25,9 & 25,9 & 25,6 & 25,1 & 24,8 & 24,5 \\
\cline { 2 - 12 } & Ankara & 23,7 & 23,9 & 24,2 & 24,7 & 25,3 & 25,6 & 26,5 & 26,9 & 25,6 & 24,8 & 24,2 & 23,9 \\
\cline { 2 - 11 } & Erzurum & 23,3 & 23,4 & 23,9 & 24,4 & 24,6 & 25,5 & 26,6 & 26,5 & 25,4 & 24,6 & 24,2 & 23,6 \\
\hline
\end{tabular}




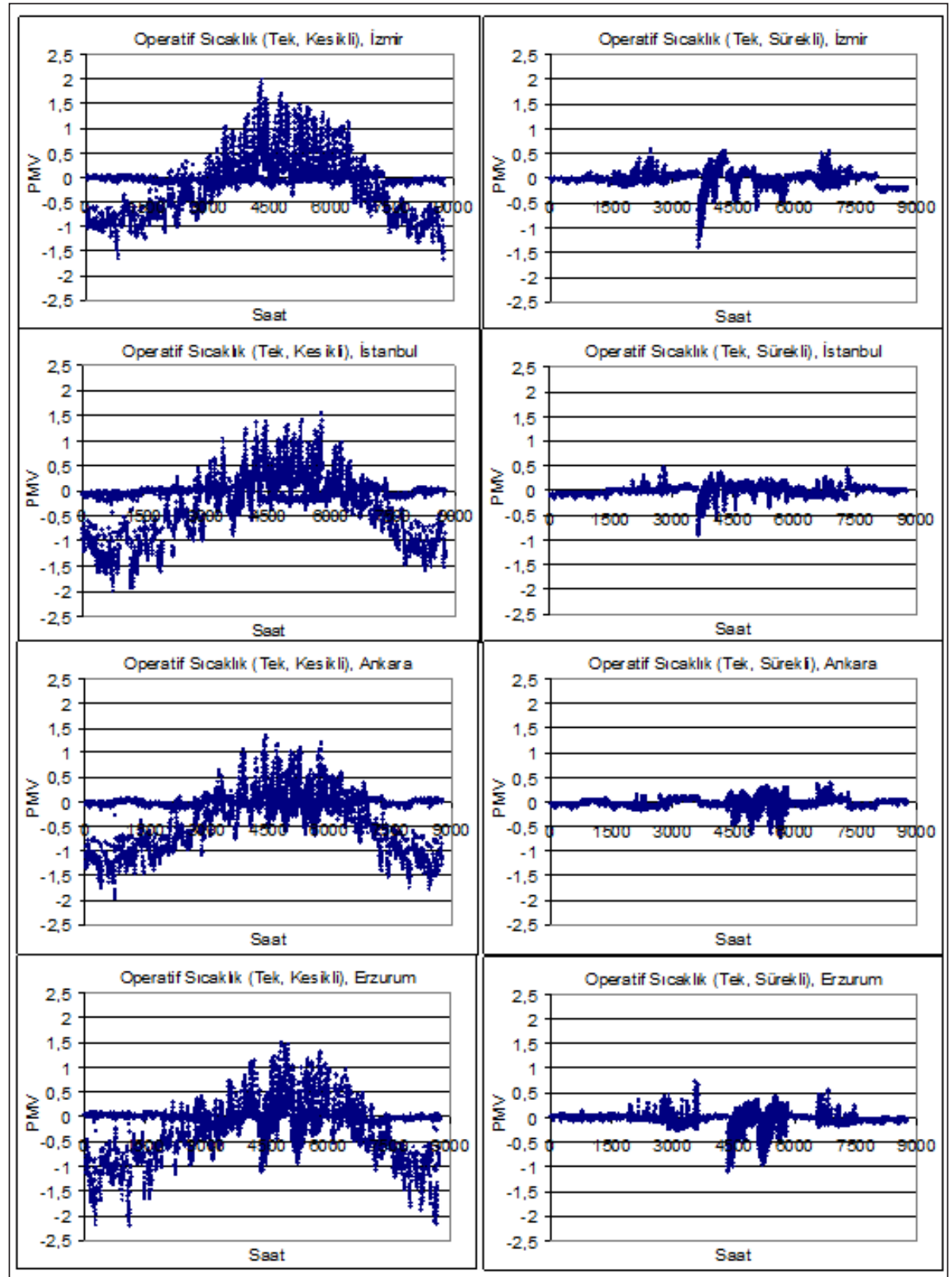

Şekil 4. Saatlik PMV Değerleri

$P M V=0$ için operatif set sıcaklık aralıkları kesikli rejim için İzmir'de $24,5-26,0^{\circ} \mathrm{C}$, İstanbul'da $24,2-26,0^{\circ} \mathrm{C}$, Ankara'da $23,6-26,5^{\circ} \mathrm{C}$ ve Erzurum'da $23,3-26,4^{\circ} \mathrm{C}$ olarak 

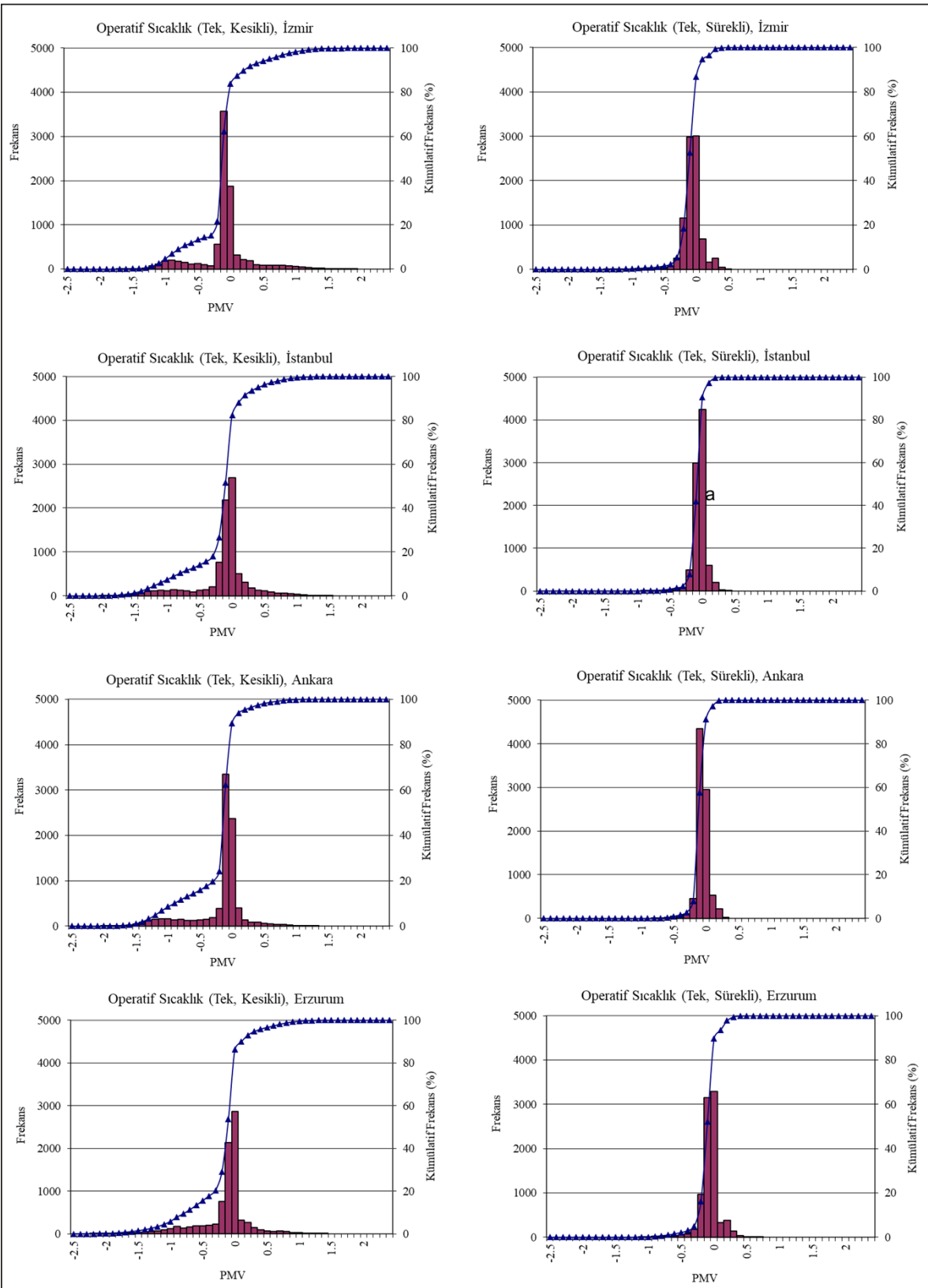

Şekil 5. PMV Dağıım Frekansları 
belirlenmiştir. Dış hava sıcaklığının yıl boyunca en yüksek olduğu İzmir'de clo değerleri diğer illere göre düşüktür. Konfor koşullarının sağlanması için gerekli olan operatif sıcaklıklar, kış aylarında İzmir'de en yüksek ve yaz aylarında ise İstanbul'da en düşük olarak gözlenmektedir. HVAC sisteminin sürekli rejimde çalıştırılması durumunda elde edilen aylık tek operatif set sıcaklık değerleri; İzmir'de $24,5-26,8^{\circ} \mathrm{C}$, İstanbul' da $24,2-26,5^{\circ} \mathrm{C}$, Ankara' da $23,7-26,9^{\circ} \mathrm{C}$ ve Erzurum' da $23,3-26,6^{\circ} \mathrm{C}$ olarak, kesikli rejimde elde edilen değerler ile yaklaşık olarak benzer şekilde bulunmuştur.

Bir yıl için PMV=0 yapan operatif sıcaklıklar (giriş verisi) ve ailenin konutta bulunduğu saatler için çalıştırılan simülasyonlarda elde edilen saatlik PMV değerleri (çıkış verisi) her il için Şekil 4'de verilmiştir. Tablo 4'e göre aile y1lın \%73'ünü (6411 saat) konutta geçirmektedir. Saatlik PMV değerlerinin istatistiksel değerlendirilmesi sonucu PMV dağılım frekansları ve kümülatif frekansları Şekil 5 'te, dağılım özellikleri ise Tablo 8'de verilmiştir.

Kesikli rejimde, giriş verisinin $\mathrm{PMV}=0$ olmasına rağmen, Şekil 4 ve 5 ile Tablo 8'den görüleceği gibi Erzurum için 1,8 PMV aralığında bir dağılım gerçekleşmektedir. Dağılım aralığı büyüdükçe standard sapma da büyümektedir. Erzurum'da ailenin evde bulunduğu saatlerin \%89,4'ü EN15251 [2]'a göre belirlenen dört 1sıl konfor kategorisinde en yüksek memnuniyet seviyesi olan $-0,2<\mathrm{PMV}<+0,2$ aralığına, \%98,0'i ise normal beklenti seviyesi olan $-0,5<\mathrm{PMV}<+0,5$ aralığına düşmektedir. Diğer iller için de benzer değerler elde edilmiştir (Tablo 8).

Sürekli rejimde ise PMV dağılımı İzmir için 2,0, Ankara için 1,1 PMV aralığında

Tablo 8. Ailenin Konutta Bulunduğu Saatlerde PMV=0'ı Sağlayan Operatif Sıcaklıklarda Elde Edilen Dağılım Özellikleri

\begin{tabular}{|l|r|r|r|r|r|r|r|r|}
\hline & \multicolumn{4}{|c|}{ Kesikli } & \multicolumn{4}{c|}{ Sürekli } \\
\hline & \multicolumn{1}{|c|}{ İzmir } & İstanbul & Ankara & Erzurum & \multicolumn{1}{c|}{ İzmir } & İstanbul & Ankara & Erzurum \\
\hline Ortalama & $-0,0087$ & $-0,0007$ & $-0,0220$ & $-0,0176$ & $-0,3886$ & 0,0011 & $-0,0176$ & $-0,0240$ \\
\hline Ortadaki değer & $-0,0300$ & 0,0097 & $-0,0197$ & 0,0036 & $-0,4205$ & 0,0136 & $-0,0226$ & $-0,0026$ \\
\hline Standard sapma & 0,1167 & 0,1422 & 0,1073 & 0,1536 & 0,3515 & 0,1090 & 0,1014 & 0,1530 \\
\hline Varyans & 0,0136 & 0,0202 & 0,0115 & 0,0236 & 0,1235 & 0,0119 & 0,0103 & 0,0234 \\
\hline En küçük değer & $-0,6890$ & $-0,8947$ & $-0,7539$ & $-1,0953$ & $-1,1355$ & $-0,8947$ & $-0,7251$ & $-1,0953$ \\
\hline En büyük değer & 1,0122 & 0,8071 & 0,4413 & 0,7231 & 0,8669 & 0,4705 & 0,3928 & 0,7297 \\
\hline Aralık & 1,7 & 1,7 & 1,2 & 1,8 & 2,0 & 1,4 & 1,1 & 1,8 \\
\hline$-0,2<$ PMV<+0,2 & 94,1 & 89,2 & 94,5 & 89,4 & 89,8 & 94,4 & 94,3 & 89,3 \\
\hline$-0,5<P M V<+0,5$ & 98,9 & 98,8 & 99,0 & 98,0 & 98,5 & 99,4 & 99,4 & 98,0 \\
\hline
\end{tabular}


Hancioğlu, Kuzgunkaya, E., Yildirim, N., Gokçen, Akkurt, G.,

\begin{tabular}{|c|c|c|c|c|c|c|c|c|c|c|c|c|c|c|c|c|}
\hline \multirow{4}{*}{$\begin{array}{l}\text { 톤 } \\
\text { 녹 } \\
\text { 离 }\end{array}$} & \multirow{2}{*}{ 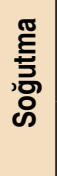 } & $\omega$ & 0 & 0 & 0 & 0 & 0 & $\stackrel{\nabla_{-}}{-}$ & $\stackrel{2}{=}$ & $\stackrel{\Xi}{\sigma}$ & $\stackrel{m}{-}$ & 0 & 0 & 0 & $\stackrel{\bullet}{10}$ & \\
\hline & & Y & 0 & 0 & 0 & 0 & 0 & $\stackrel{\circ}{\sim}$ & $\stackrel{m}{=}$ & $\stackrel{\sim}{\sim}$ & $\stackrel{\infty}{\infty}^{\infty}$ & 0 & 0 & 0 & $\stackrel{m}{\sim}$ & \\
\hline & \multirow{2}{*}{ 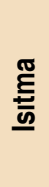 } & $\boldsymbol{\infty}$ & $\stackrel{g}{\mathbb{f}^{\prime}}$ & $\begin{array}{l}\mathscr{0} \\
\stackrel{0}{0}\end{array}$ & $\begin{array}{l}\infty \\
\stackrel{\infty}{0}\end{array}$ & $\begin{array}{l}0 \\
\infty^{-}\end{array}$ & $\begin{array}{l}\infty \\
\infty \\
\infty\end{array}$ & ఫ্ & 0 & 0 & $\overbrace{\infty}^{\circ}$ & \begin{tabular}{l}
\multirow{2}{*}{} \\
$\stackrel{5}{2}$
\end{tabular} & $\begin{array}{l}\text { m } \\
\infty^{\circ}\end{array}$ & $\begin{array}{l}10 \\
0 \\
8\end{array}$ & $\begin{array}{l}\text { m } \\
\infty \\
\infty\end{array}$ & \\
\hline & & Y & 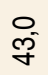 & 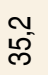 & $\hat{\mathbb{N}}$ & $\begin{array}{l}\circ \\
\infty \\
\infty\end{array}$ & $\begin{array}{l}\infty \\
\infty\end{array}$ & סָ & 0 & 0 & $\stackrel{\bullet}{6}$ & 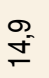 & $\frac{N}{N}$ & $\overline{\sigma^{\prime}}$ & $\begin{array}{l}\text { N } \\
\text { స̃ }\end{array}$ & \\
\hline \multirow{4}{*}{ 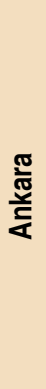 } & \multirow{2}{*}{$\begin{array}{l}\stackrel{\mathbb{E}}{5} \\
\text { 志 } \\
\text { க }\end{array}$} & ( ) & 0 & 0 & 0 & 0 & ס̊ & $\underset{\sim}{\stackrel{\Delta}{*}}$ & $\stackrel{\infty}{-}$ & $\cong$ & $\stackrel{\sim}{\tau}$ & 0 & 0 & 0 & $\overline{0}$ & \\
\hline & & $\underline{x}$ & 0 & 0 & 0 & 0 & $\stackrel{m}{0}$ & $=$ & $\cong$ & $\cong$ & $\stackrel{\infty}{\infty}$ & 0 & 0 & 0 & 은 & \\
\hline & \multirow{2}{*}{ 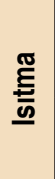 } & $\infty$ & $\frac{0}{\frac{\sigma}{\sigma}}$ & $\frac{N}{m}$ & ㅇ. & 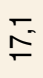 & $\stackrel{\cong}{=}$ & $\widehat{\sigma}$ & 0 & 0 & ఠ) & $\stackrel{+}{\infty}$ & $\bar{\phi}$ & $\begin{array}{l}\text { o } \\
\text { ळ్ }\end{array}$ & $\begin{array}{l}\text { న్ } \\
\text { స్ }\end{array}$ & \\
\hline & & $\underline{x}$ & 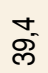 & ब্ & $\overline{\mathbb{N}}$ & $\stackrel{m}{6}$ & $\stackrel{\text { m}}{\circ}$ & $\hat{\omega}$ & 0 & 0 & $\mathscr{C}^{\circ}$ & 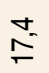 & $\begin{array}{l}\infty \\
\stackrel{\infty}{\infty}\end{array}$ & હ & $\frac{\dot{J}}{\stackrel{\Delta}{\sim}}$ & \\
\hline \multirow{4}{*}{ 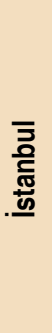 } & \multirow{2}{*}{ 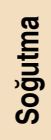 } & n & 0 & 0 & 0 & 0 & $\stackrel{\infty}{0}$ & $\stackrel{\circ}{-}$ & $\stackrel{0}{\sim}$ & $\stackrel{\text { m }}{\text { N }}$ & $\stackrel{m}{-}$ & 0 & 0 & 0 & $\stackrel{\circ}{\sim}$ & \\
\hline & & $\underline{x}$ & 0 & 0 & 0 & 0 & 10 & $\stackrel{\infty}{0}$ & $\stackrel{\sim}{\sim}$ & $\bar{\sim}$ & $\stackrel{8}{0}$ & 0 & 0 & 0 & $\begin{array}{c}\infty \\
0^{-}\end{array}$ & \\
\hline & \multirow{2}{*}{$\begin{array}{l}\underset{\underline{\underline{E}}}{\underline{\underline{w}}} \\
\underline{\underline{\underline{0}}}\end{array}$} & $\infty$ & 足 & $\overline{\tilde{ల}}$ & ని & $\begin{array}{l}\mathscr{0} \\
\mathscr{\sigma}^{-}\end{array}$ & O) & 0 & 0 & 0 & ஜ) & $\hat{F}$ & $\overline{\mathrm{d}}$ & ণ্লি & $\begin{array}{l}\text { 오 } \\
\text { চे }\end{array}$ & \\
\hline & & $\underline{x}$ & స్ల & $\stackrel{m}{\circ}$ & 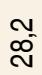 & & $\infty^{\circ}$ & 0 & 0 & 0 & 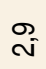 & $\stackrel{\sim}{\simeq}$ & $\hat{\sim}$ & $\begin{array}{l}\infty \\
\text { c. }\end{array}$ & ㅇ. & \\
\hline \multirow{4}{*}{ 言 } & \multirow{2}{*}{ 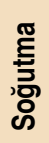 } & $\boldsymbol{\infty}$ & 0 & 0 & 0 & 0 & $\stackrel{\nabla}{=}$ & $\stackrel{\circ}{\circ}$ & $\stackrel{\text { s) }}{\mathrm{N}}$ & $\stackrel{\infty}{\sim}$ & $\stackrel{\text { N }}{ }$ & 0 & 0 & 0 & $\frac{O}{E}$ & \\
\hline & & $\underline{Y}$ & 0 & 0 & 0 & 0 & $=$ & $\stackrel{m}{\sim}$ & $\stackrel{\infty}{\sim}$ & $\stackrel{+}{\sim}$ & $\underset{-}{ \pm}$ & 0 & 0 & 0 & $\begin{array}{l}\circ \\
\text { 음 }\end{array}$ & \\
\hline & \multirow{2}{*}{$\frac{\text { 똩 }}{\underline{\underline{E}}}$} & $\infty$ & $\begin{array}{l}\infty \\
\text { ণ্ }\end{array}$ & $\stackrel{n}{N}$ & $\hat{\bar{N}}$ & $\bar{\nabla}$ & \% & 0 & 0 & 0 & $\stackrel{\sim}{\text { m }}$ & 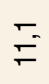 & $\stackrel{n}{\stackrel{0}{\sim}}$ & S & $\begin{array}{l}0 \\
\stackrel{\Delta}{\sigma}\end{array}$ & \\
\hline & & $\underline{x}$ & $\begin{array}{l}\text { o } \\
\text { ô }\end{array}$ & $\overline{\mathrm{N}}$ & $\frac{O}{i}$ & $\hat{\underline{m}}$ & $\stackrel{\infty}{\infty}^{-}$ & 0 & 0 & 0 & ָ̃ & $\bar{\simeq}$ & ָ̃ & $\begin{array}{l}\text { o } \\
\text { ô }\end{array}$ & $\begin{array}{l}\text { ద } \\
\infty \\
0 \\
0\end{array}$ & 文 \\
\hline$\stackrel{\text { ప্ }}{=}$ & \begin{tabular}{l} 
ธ్ \\
\multirow{心}{*}{}
\end{tabular} & 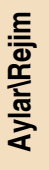 & 总 & $\begin{array}{l}\overline{\widetilde{\pi}} \\
\vec{B} \\
\text { 心. }\end{array}$ & 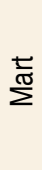 & 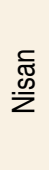 & 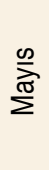 & 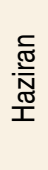 & 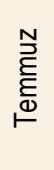 & 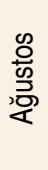 & 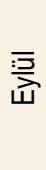 & $\frac{\frac{E}{5}}{\frac{H}{W}}$ & 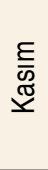 & $\frac{\underline{\underline{\bar{T}}}}{\frac{\mathrm{d}}{\alpha}}$ & 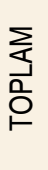 & 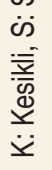 \\
\hline
\end{tabular}




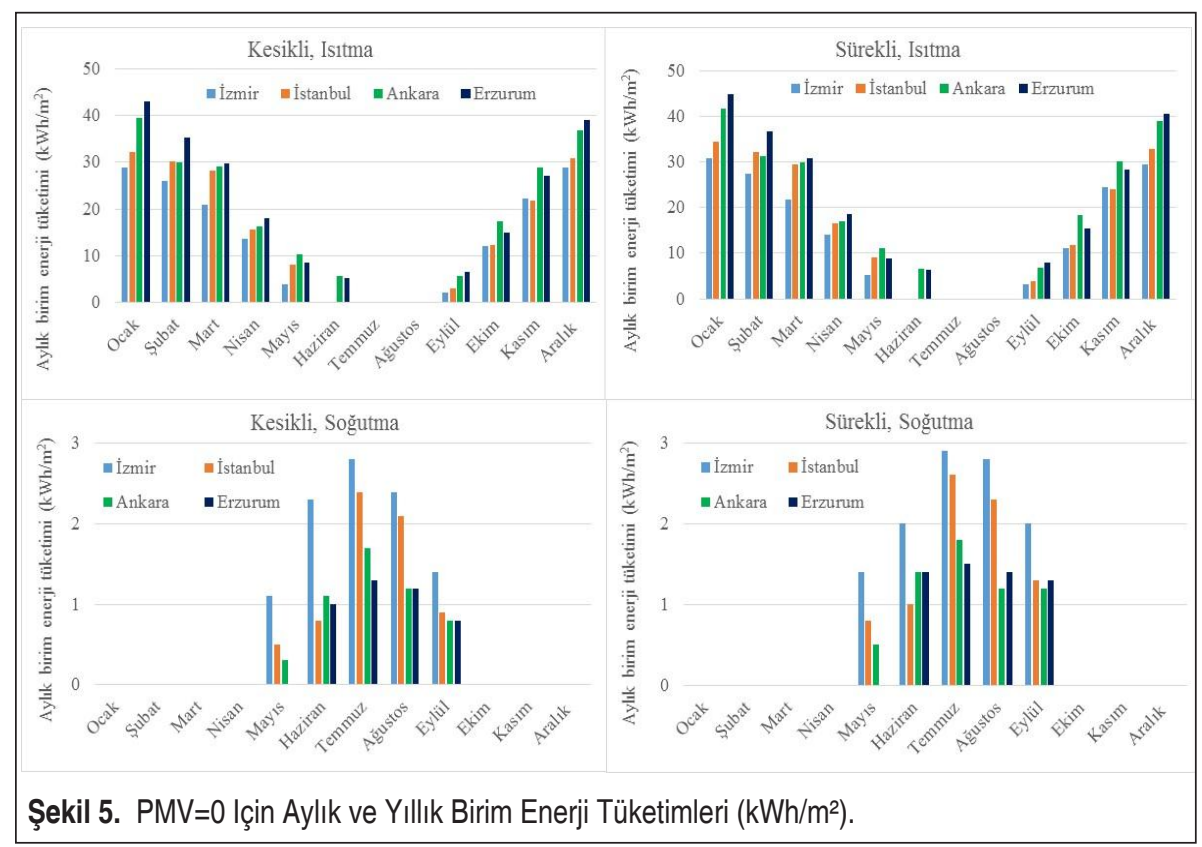

gerçekleşmektedir. İzmir'de ailenin evde bulunduğu saatlerin $\% 89,9$ 'u en yüksek memnuniyet seviyesi olan $-0,2<\mathrm{PMV}<+0,2$ aralığına düşmektedir. İstanbul'da aynı PMV aralı̆̆ için bu oran \%94,4, Ankara'da \%94,3, Erzurum'da ise \%89,3’tür. Normal memnuniyet seviyesini gösteren $-0,5<\mathrm{PMV}<+0,5$ aralığına ise evde bulunulan saatlerin İzmir'de \%98,5'u, İstanbul'da \%99,4'ü, Ankara'da \%99,4'ü, Erzurum'da ise $\% 98$ 'i düşmektedir (Tablo 8).

Her bir il için belirlenen ve PMV'yi sıfır yapan aylık operatif sıcaklık set değerleri için simülasyonlar aylık olarak tekrarlanmış ve aylık ısıtma/soğutma enerji tüketimleri birim alan için kesikli ve sürekli rejim için belirlenmiştir. $\mathrm{PMV}=0$ yapan değerler

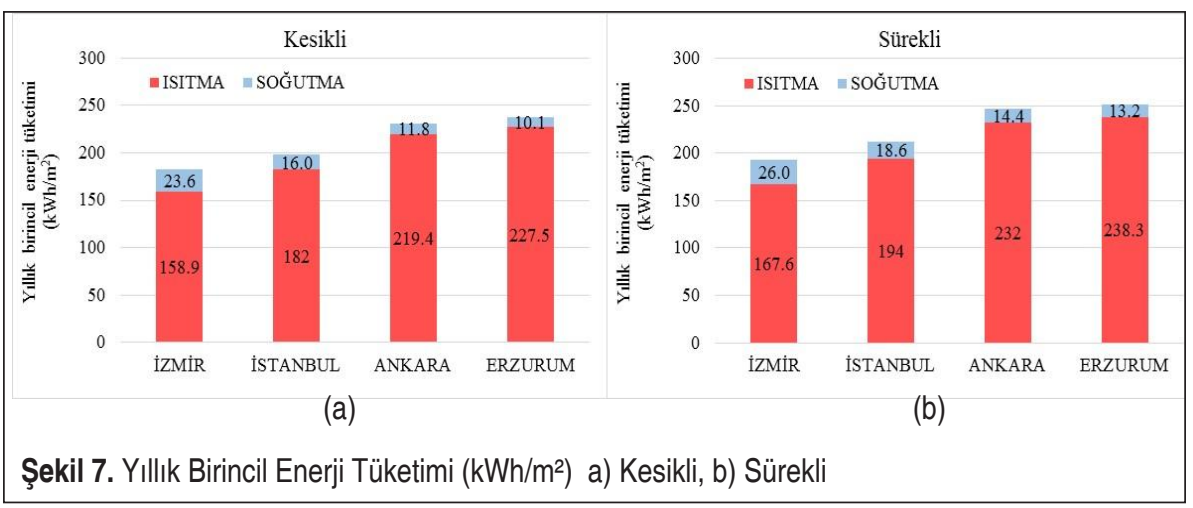


için İzmir, İstanbul, Ankara ve Erzurum illeri için aylık birim enerji tüketimleri Tablo 9'da verilmiş ve Şekil 6'da gösterilmiştir.

Her il için konutta tüketilen doğalgaz yıllık enerji tüketimi (Tablo 9-Isıtma) 1,0, elektrik yıllık enerji tüketimi (Tablo 9-Soğutma) 2,36 birincil enerji dönüşüm faktörü ile çarpılarak yıllık 1sıtma/soğutma birincil enerji tüketimi hesaplanmış ve Şekil 7'de gösterilmiştir.

$P M V=0$ için operatif sıcaklık aralıkları tüm illerde birbirine yakın olmasına rağmen 1sıtma/soğutma enerji tüketimlerinin birbirinden farklı olduğu görülmektedir. Kesikli rejimde, 1sıtma enerji tüketimi Erzurum'da en yüksek, İzmir' de en düşük iken, soğutma enerji tüketimi de tersi olarak İzmir'de en yüksek, Erzurum'da en düşüktür. Bu da dış hava sıcaklıklarının enerji tüketimi üzerindeki etkisini ortaya koymaktadır. Tablo 9 ve Şekil 7'den açıkça görüldüğü üzere, kesikli rejim ile sürekli rejim karşılaştırıldığında enerji tüketim değerlerinin ısıtmada \% 4,5-6,2, soğutmada ise \% 9,3-24,1 arasında arttığı görülmektedir. Soğutma enerji tüketimi artışı 1sıtmaya göre daha yüksek olmaktadır. Bu artış Ankara ve Erzurum'da sırasıyla \%18 ve \%23,2'dir.

\section{TARTIŞMA VE ÖNERILER}

Bu çalışmada, konutlarda 1sıl konfor koşulları ile 1sıtma/soğutma enerji tüketimleri arasındaki ilişki analiz edilmiştir. Bu çalışma kapsamında TS 825 [36]'de belirlenen Türkiye'nin farklı iklim bölgelerini temsil eden dört il için bir örnek konut tasarlanmıştır. DesignBuilder yazılımı kullanılarak, tam mekanik kontrollu HVAC sistemi (doğal havalandırma yok)'nde kesikli ve sürekli rejimlerde, aylık tek ısıtma/soğutma operatif sıcaklık set değerleri için yıl boyunca ailenin evde bulunduğu saatlerde PMV konfor koşullarını da değerlendirerek, birim 1sıtma/soğutma enerji tüketimleri, birim birincil enerji tüketimleri hesaplanmıştır. Elde edilen sonuçlar aşağıda özetlenmiştir:

Kesikli rejimde belirlenen aylık operatif set sıcaklıkları İzmir $\left(24,5-26,0^{\circ} \mathrm{C}\right)$ ve İstanbul $\left(24,2-26,0^{\circ} \mathrm{C}\right)$ için biribirine yakınken aynı durumda Ankara $\left(23,6-26,5^{\circ} \mathrm{C}\right)$ ve Erzurum'da $\left(23,3-26,4^{\circ} \mathrm{C}\right)$ gözlenmektedir. Sürekli rejimde ise kış sezonu için sıcaklıklarda büyük fark olmamasına karşın yaz sıcaklıklarında İzmir $\left(24,5-26,8^{\circ} \mathrm{C}\right)$ ve İstanbul $\left(24,2-26,5^{\circ} \mathrm{C}\right)$ 'da yükselme gözlenmektedir.

PMV=0'1 sağlayan operatif set sıcaklıkları için elde edilen yıllık birim 1sıtma/soğutma enerji tüketimleri karşılaştırılmıştır. Sürekli rejim uygulandığında birim enerji tüketiminde artış olduğu belirlenmiştir. Sürekli rejim kesikli rejime göre 1sıtma enerji tüketiminde \% 4,5-6,2, soğutma enerji tüketiminde ise \% 9,1-23,2 daha yüksektir. Soğutma enerjisi tüketiminde en yüksek artış ile isıtma enerjisi tüketimindeki en düşük artış Erzurum'dadır.

$P M V=0$ yapan operatif sıcaklıkların giriş verisi olarak kullanıldığı simülasyonlar- 
dan elde edilen saatlik PMV değerlerinin istatistiksel analizinde, İzmir ili için kesikli rejimde çalışmanın sürekli rejime göre $-0,5<\mathrm{PMV}<+0,5$ konfor aralığında $\% 0,4$ ve $-0,2<\mathrm{PMV}<+0,2$ aralığında ise $\% 4,3$ daha iyi sonuç verdiği görülmektedir (Tablo 8). İstanbul için sürekli rejimde yapılan hesaplamalara bakıldığında ise hem $-0,2<\mathrm{PMV}<+0,2$ konfor aralığında $(\% 5,2)$ hemde $0,5<\mathrm{PMV}<+0,5$ konfor aralığında $(\% 0,6)$ daha yüksek değerleri görmekteyiz. Kesikli rejimde $-0,2<\mathrm{PMV}<+0,2$ konfor aralığında Ankara ve Erzurum illeri \%0,1-0,2 ve sürekli rejimde -0,5<PMV $<+0,5$ konfor aralığında Ankara ili \%0,4 daha fazla memnuniyetle sonuçlanmaktadır.

Aynı koşullar için verilen frekans dağılımlarında PMV aralıklarının kesikli çalışma rejiminde sürekli rejime göre daha büyük olduğu görülmektedir. Bu durumda standart sapma da büyümektedir. Tüm güne ait PMV değerlerinde dolayısı ile konfor koşullarında sürekli rejimde kesikli rejime göre önemli bir iyileşme olduğunu göstermektedir.

İncelenen tüm çalışma rejimleri ve kontrol stratejilerinde dış hava sıcaklıkları azaldıkça enerji tüketimindeki değişimin daha fazla olduğu, en dramatik değişikliklerin Erzurum'da gerçekleştiği görülmüştür.

Çeşitli çalışma rejimleri ve HVAC kontrol stratejilerinde elde edilecek konfor koşulları ile enerji tüketimlerinin karşılaştırıldığı bu çalışmanın; konut sahipleri ile konut tasarlayan ve tesisatını gerçekleştiren mimar ve mühendislere tercih edilen konfor koşullarında mevcut enerji tasarrufu potansiyelini göstermek ve enerji tüketiminin konfor koşulları ile birlikte değerlendirilmesi konusunda yol gösterici olacağına inanıyoruz.

\section{TEŞEKKÜR}

Projeyi maddi olarak destekleyen Türk Tesisat Mühendisleri Derneği (TTMD)'ne teşekkür ederiz.

\section{KAYNAKÇA}

1. Fanger, PO. 1970. Thermal Comfort Analyses and Applications in Environmental Engineering, McGraw-Hill, London.

2. EN 15251, 2007. Indoor Environmental Input Parameters for Design and Assessment of Energy Performance of Buildings Addressing Indoor Air Quality, Thermal Environment, Lighting and Acoustics.

3. EN ISO 7730, 2005. Ergonomics of the Thermal Environment- Analytical Determination and Interpretation of Thermal Comfort Using Calculation of the PMV and PPD Indices and Local Thermal Comfort Criteria.

4. Corgnati, SP., Fabrizio, E., Filippi, M. 2008. "The impact of indoor thermal conditions, system controls and building types on the building energy demand", Energy Buildings, 40, 627-636, doi: 10.1016/j.enbuild.2007.04.017. 
5. Becker, R., Goldberger, I., Paciuk, M. 2007. "Improving energy performance of school buildings while ensuring indoor air quality ventilation", Building and Environment, 42, 3261-3276, doi: 10.1016/j.buildenv.2006.08.016.

6. Van der Linden, K., Boerstra, AC., Raube, AK., Kurvers, SR. 2002. "Thermal indoor climate building performance characterized by human comfort response", Energy Buildings, 34, 737-744, doi: 10.1016/S0378-7788(01)00144-X.

7. Huh, J., Brandemuehl, MJ. 2008. "Optimization of air-conditioning system operating strategies for hot and humid climates”, Energy Buildings, 40, 1202-1213, doi: 10.1016/j.enbuild.2007.10.018

8. Atmaca, I., Kaynakli, O., Yigit, A. 2007. "Effects of radiant temperature on thermal comfort", Building and Environment, 42, 3210-3220, doi: 10.1016/j.buildenv.2006.08.009.

9. ANSI/ASHRAE Standard 55, 2017. Thermal Environmental Conditions for Human Occupancy.

10. Koç, A., Yağlı, H., Koç, Y., Uğurlu, İ. 2018. “Dünyada ve Türkiye'de Enerji Görünümünün Genel Değerlendirilmesi”, Mühendis ve Makina, 59, 692, 86-114.

11. EU Directive 2018/844. 2018. https://eur-lex.europa.eu/legal-content/EN/TXT/PDF /?uri=CELEX:32018L0844\&from=EN son erişim tarihi: 22.07.2020.

12. ISO 13790, 2008. Energy Performance of buildings- Calculation of Energy Use for Space Heating and Cooling.

13. Yang, KH., Su, CH. 1997. "An approach to building energy savings using the PMV index", Building and Environment, 32 (1), 25-30, doi: 10.1016/S03601323(96)00027-3.

14. Karyono, TH. 2000. "Report on thermal comfort and building energy studies in Jakarta-Indonesia", Building and Environment, 35 (1), 77-90, doi: 10.1016/S03601323(98)00066-3.

15. Hanqing, W., Chunhua, H., Zhiqiang, L., Guangfa, T., Yingyun, L., Zhiyong, W. 2006. "Dynamic evaluation of thermal comfort environment of airconditioned buildings", Building and Environment, 41 (11), 1522-1529, doi: 10.1016/j.buildenv.2005.06.002.

16. Tham, KW., and Ullah, MB. 1993. Building energy performance and thermal comfort in Singapore. ASHRAE Transactions, 99 (1), 308-321.

17. Holz, R., Hourigan, A., Sloop, R., Monkman, P., Krarti, M. 1997. "Effects of standard energy conserving measures on thermal comfort", Building and Environment, 32:1, 31-43, doi: 10.1016/S0360-1323(96)00025-X.

18. Karlsson, JF., Moshfegh, B. 2005. "Energy demand and indoor climate in a low energy building-changed control strategies and boundary conditions", Energy Buildings, 38, 315-326, doi: 10.1016/j.enbuild.2005.06.013. 
19. Arslanoğlu, N., Yiğit, A. 2011. "The Effect Of Different Indoor Air Velocities And Temperatures On Thermal Comfort”, Isı Bilimi ve Tekniği Dergisi, 31, 2, 95-100.

20. Abdallah, M., Clevenger, C. Golparvar-Fard, M. 2015. "Developing a Thermal Comfort Report Card for Building”, Procedia Engineering, 118, 675 - 682, doi: 10.1016/j.proeng.2015.08.502.

21. Zinzi, M., Carnielo, E. 2017. "Impact of urban temperatures on energy performance and thermal comfort in residential buildings. The case of Rome, Italy", Energy Buildings, 157, 20-29, doi: 10.1016/j.enbuild.2017.05.021.

22. Zhaoa, Z., Houchatia, M., Beitelmala, A. 2017. "An Energy Efficiency Assessment of the Thermal Comfort in an Office building”, Energy Procedia, 134, 885-893, doi: 10.1016/j.egypro.2017.09.550.

23. Irulegia, O., Ruiz-Pardo, A., Serra, A., Salmerón, JM., Vega, R. 2017. "Retrofit Strategies Towards Net Zero Energy Educational Buildings: A case Study At The University Of The Basque Country", Energy Buildings, 144, 387-400, https://doi. org/10.1016/j.enbuild.2017.03.030.

24. Gagnona, R., Gosselina, L., Decker, S. 2018. "Sensitivity analysis of energy performance and thermal comfort throughout building design process", Energy Buildings, 164, 278-294, doi: 10.1016/j.enbuild.2017.12.066.

25. Yun, GY. 2018. "Influences of perceived control on thermal comfort and energy use in buildings", Energy Buildings, 158, 822-830, doi: 10.1016/j.enbuild.2017.10.044.

26. Abreu-Harbich, LV., Chaves, VLA. Brandstetter, MCGO. 2018. "Evaluation of strategies that improve the thermal comfort and energy saving of a classroom of an institutional building in a tropical climate", Building and Environment,135, 257268, doi: 10.1016/j.buildenv.2018.03.017.

27. Ozkan, A., Kesik, T., Yilmaz, AZ., O'Brien, W. 2019. "Development and visualization of time-based building energy performance metrics", Building Research \& Information, 47:5, 493-517, doi: 10.1080/09613218.2018.1451959.

28. Camacho-Montano, SC., Wagner, A., Erhorn-Kluttig, H., Mumovic, D., Summerfield, A. 2019. "Clearing the air on EU guidance projects for school buildings", Building Research \& Information, 47:5, 624-634, doi: 10.1080/09613218.2018.1448961.

29. Pathirana, S., Rodrigo, A., Halwatura, R. 2019. "Efect of building shape, orientation, window to wall ratios and zones on energy efciency and thermal comfort of naturally ventilated houses in tropical climate", International Journal of Energy and Environmental Engineering, 10:107-120, https://doi.org/10.1007/s40095-0180295-3.

30. Dong, Z., Boyi, Q., Chunlong, W. 2019. "Energy-saving evaluation and control optimization of an ASHP heating system based on indoor thermal comfort", Solar Energy, 194, 913-922, doi: 10.1016/j.solener.2019.11.042. 
31. Ming, R., Yu, W., Zhao, X., Liu, Y., Li, B., Essah, E., Yao, R. 2020. “Assessing energy saving potentials of office buildings based on adaptive thermal comfort using a tracking-based method", Energy Buildings, 208, 109611, doi: 10.1016/j.enbuild.2019.109611.

32. Koyun, T., ve Ersin, K. O. Ç. 2017. "Bir Binanın Değişken Cam ve Dış Duvar Tiplerine Göre Pencere/Duvar Alanı Oranlarının Bina Isı Kayıplarına Etkisi”,Mühendis ve Makina, 58, 688, 1-14.

33. Haydaraslan, E., Çuhadaroğlu, B., Yaşar, Y. 2020. "Kat Isıtmasında Yüzer Döşeme ve Faz Değiştiren Malzeme Kullanımının Enerji Verimliliğine ve Konfor Koşullarına Etkisi”, Mühendis ve Makina, 61, 700, 180-197.

34. Buyruk, E., Fertelli, A., Karabulut, K. 2013. "Farklı Yalıtım Uygulamalarının Isı Kaybına Olan Etkilerinin Deneysel ve Sayısal İncelenmesi”, Tesisat Mühendisliği, $136,53-64$.

35. Buyruk, E., Kılınc, F., Karabulut, K., Caner, M., Bostancı, A. E. 2017. "Investigation of the Effect of Insulation Thickness on Energy Saving by Using Thermography”, 8th International Advanced Technologies Symposium, Elazı ̆̆, Turkey.

36. TS 825, 2008. Binalarda Isı Yalıtım Kuralları.

37. Eskin, N., Turkmen, H. 2008. "Analysis of annual heating and cooling energy requirements for office buildings in different climates in Turkey", Energy Buildings, 40, 763-773, https://doi.org/10.1016/j.enbuild.2007.05.008.

38. Inanici, MN., Demirbilek, FN. 2000. "Thermal performance optimization of building aspect ratio and south window size in five cities having different climatic characteristics of Turkey", Building and Environment, 35, 41-52, doi: 10.1016/S03601323(99)00002-5.

39. Uçar, A., Balo, F. 2009. "Effect of fuel type on the optimum thickness of selected insulation materials for the four different climatic regions of Turkey", Applied Energy, 86, 730-736, doi: 10.1016/j.apenergy.2008.09.015.

40. Oral, KO., and Yılmaz, Z. 2003. "Building form for cold climatic zones related to building envelope from heating energy conservation point of view", Energy Buildings, 35, 383-388, doi: 10.1016/S0378-7788(02) 00111-1.

41. Kaya, M., Fırat, İ., Çomaklı, Ö. 2016. "Erzincan İlindeki Binalarda Isı Yalıtımının Enerji Tasarrufuna Etkisinin Ekonomik Analizi”, Isı Bilimi ve Tekniği Dergisi, 36, $1,47-55$.

42. Kon, O., Yüksel, B. 2016. "Farklı Amaçlarla Kullanılan Binaların Çatı, Döşeme Ve Dış Duvarları İçin Ölçülerek Hesaplanan Optimum Yalıtım Kalınlıkları”, Isı Bilimi Ve Tekniği Dergisi, 36, 1, 17-27.

43. Özcan, NY., Kuzgunkaya, E., Akkurt, GG. 2018. “Isıl Konfor Sıcaklıklarına Bağl1 
Olarak Bir Konutun Enerji Performansının Değerlendirmesi: İzmir Örneği”, Sakarya Üniversitesi Fen Bilimleri Enstitüsü Dergisi, 22 (2), 784-798, doi:10.16984/Saufenbilder.292296

44. Altun, M., Akçamete, A., Meral Akgül Ç. 2019. "D1ş sıcaklık verisinin bina 1sıtma enerji gereksinimine etkisinin ve TS 825 derece-gün bölge kümelendirmesinin geçerliliğinin incelenmesi”, Pamukkale Universitesi Mühendislik Bilimi Dergisi, doi: $10.5505 /$ pajes.2019.00334

45. EnergyPlus Engineering Reference. 2019. The Reference to EnergyPlus Calculations. https://energyplus.net/sites/all/modules/custom/nrel_custom/pdfs/pdfs_v8.9.0/ EngineeringReference.pdf

46. Aktacir, MA., Nacar, MA., Yeşilata, B. 2011. "İzmir Binalarda Enerji Verimliliği Amaçlı Yazılımlar Üzerine Kısa Bir Değerlendirme”, 10. Ulusal Tesisat Mühendisliği Kongresi, İzmir.

47. ASHRAE, 2005. Nonresidential Cooling and Heating Load Calculations, Chapter 30, ASHRAE Handbook Fundamentals, ASHRAE, Atlanta.

48. Rees, SJ., Davies, MG., Spitler, JD., Haves, P. 2000. “Qualitative comparison of North American and U.K. cooling load calculation methods”, HVAC\&Research, 6, 75-99, doi: 10.1080/10789669.2000.10391251.

49. ANSI/ASHRAE 140, 2007. Standard Method of Test for the Evaluation of Building Energy Analysis Computer Programs.

50. Design Builder Software. 2020. http://www.designbuilder.co.uk.

51. METEONORM. 2020. Global Meteorological Database for Engineers, Planners and Education, www.meteonorm.com.

52. Atmaca, M. 2017. Avrupa Birliği Bina Enerji Performansı Direktifi'nin Türkiye'deki Mevcut Otel Binaları İçin Uyarlanmasına Yönelik Bir Yaklaşım. Doktora Tezi, İstanbul Teknik Üniversitesi.

53. Ganiç, N., Yılmaz, A. Z., Corgnatı, S. P. 2013. "Enerji Performansı Gereksinimlerinin Optimum Maliyet Düzeyinin Türkiye'deki Örnek Bir Ofis Binasında Yapılan İyileştirmeler için Hesaplanması", 10. Ulusal Tesisat Mühendisliği Kongresi, İzmir.

54. TS EN 832, 2007. Binaların Isı1 Performansı-Meskenlerde Isitma Amaciyla Kullanılan Enerjinin Hesaplanması. 